\title{
Application of PLISSIT Counseling Model for Women with Cervical Cancer Undergoing Treatment on Enhancing Sexuality
}

\author{
Sahar Ahmed Shafik ${ }^{1, *}$, Shaimaa Hassan Mohamady ${ }^{2}$ \\ ${ }^{1}$ Community Health Nursing Department, Faculty of Nursing, Helwan University, Helwan, Egypt \\ ${ }^{2}$ Maternal \& Newborn Health Nursing Department, Faculty of Nursing, Helwan University, Helwan, Egypt
}

Email address:

dsahar100@yahoo.com (S. A. Shafik),dr_shaimaamohamady@yahoo.com (S. H. Mohamady)

*Corresponding author

\section{To cite this article:}

Sahar Ahmed Shafik, Shaimaa Hassan Mohamady. Application of PLISSIT Counseling Model for Women with Cervical Cancer Undergoing Treatment on Enhancing Sexuality. American Journal of Nursing Science. Vol. 5, No. 3, 2016, pp. 85-95. doi: 10.11648/j.ajns.20160503.13

Received: April 15, 2016; Accepted: April 25, 2016; Published: May 13, 2016

\begin{abstract}
Background: Sexuality is an important part of normal human functioning. Gynecological cancer diagnosis and treatment has a devastating effect on Sexual issues. The study was conducted at Outpatient oncology, Helwan General hospital, Egypt. The study aim to evaluate the effect of application of PLISSIT Counseling Model for women with cervical cancer undergoing treatment on enhancing sexuality. A quasi -experimental design was used. A purposive sample of 80 women with cervical cancer was included. Four tools, a structured interview questionnaire, body image scale, female sexual function index (FSDI), and the revised dyadic adjustment scale. The study findings indicated that a significant relationship was found between treatment, side effect pre and post application regarding nausea \& vomiting, diarrhea, and pain. The study and research hypothesis concluded that applying of PLISSIT counseling model for sexuality was effective in enhancing sexual functioning except in the area of sexual desire or libido, improvement in couple satisfaction and body image after application of PLISSIT counseling model post application compared to pre-application. The study recommended that dissemination of PLISSIT Counseling Model For Women with cervical cancer in addressing sexual dysfunction in a cancer treatment, Applying the evidence-based nursing intervention to address and manage the effects of cervical cancer on sexuality.
\end{abstract}

Keywords: Body Image, Cervical Cancer Prevention, Couple Satisfac, PLISSIT Counseling Model

\section{Introduction}

Cervical cancer (CC) is a health problem due to high rates of prevalence and mortality in women of low social and economic levels and in the productive phase of their lives, indicating a strong association of this type of cancer with precarious living conditions, low indices of human development, the absence or weakness of community education strategies (health promotion and prevention) and with the difficulty of access to public health services for the early diagnosis and treatment of precursor lesions. [1]

The second most common cancer in women worldwide is cervical cancer, with 500,000 new cases and 250,000 deaths reported each year. Approximately $80 \%$ of cases occur in developing countries, where more than $95 \%$ of women have never had a Pap test. Many of these cases can be avoided through early screening and treatment, and now also through vaccination against human papillomavirus (HPV), the virus that can lead to cervical cancer. [2]

Sexuality is a complex, Sexual and reproductive health and well-being are essential if people are to have responsible, safe, and satisfying sexual lives. Sexual health requires a positive approach to human sexuality and an understanding of the compound factors that shape human sexual behavior. These factors affect whether the expression of sexuality leads to sexual health and well-being or to sexual behaviors that put people at risk or make them vulnerable to sexual and reproductive ill-health. Health program managers and care 
providers need to understand, promote the potentially positive role sexuality can play in people's lives and to build health services that can promote sexually healthy societies. [3] Sexual health problems are higher in oncology patients, especially in those with cervical cancer and gynecological cancers. [4]

The term "body image" reflects how to feel your body is aesthetically and how attractive perceive yourself. Throughout history, humans have regarded the beauty of the human body as important. What regard as society's standards may not always correspond to the perception of our own body. [5] Cervical cancer diagnosis and treatment can bring changes related to a person's body image and sexuality, which in turn can have a devastating on intimate relationships. [6]

The experience of cancer and treatment can dramatically change aspects of a person's body, causing hair loss, extreme weight loss, changes in skin color, surgical scars and much else besides. For young people going through this, the dissatisfaction, whether temporary or permanent, can become even more extreme. [7]

In gynecological cancer, reported that between $30 \%$ and $63 \%$ of the women who underwent treatment for cervical cancer experienced some sexual problems and most of the women are at greater risk for developing vaginal stenosis and agglutination within the first three months of radiotherapy. [8]

The National Health and Social Life Survey propose that $43 \%$ of all women are affected by some form of female sexual dysfunction (FSD). [8] This number is strong, higher in women with gynecologic desire, a lack of responsive desire absent sexual thoughts or fantasies. FSD includes sexual desire disorder female orgasmic disorder, sexual arousal disorder, and sexual pain disorders. [9]

Egypt is a country where sexuality is not talking, about within the family; sexual education is not included in the curriculum of schools. Sexuality is regarded as shameful and guilty in this community that is becoming more and more conservative. Lack of sexual health education in the curriculum of schools giving health education causes problems regarding the assessment of a patient's sexual health, the discussion of their sexual problems and to provide counseling for health personnel who are responsible for the nursing and treatment of patients. [10]

PLISSIT counseling model. A guideline used to assess and manage sensitive psychoscoial issues, among them issues relating to adult sexuality. The PLISSIT method consists of four steps. 1. The practitioner obtains Permission to begin a discussion about sensitive issues. 2. Limited Information is provided to the patients. 3 . As trust is gained and the patient becomes receptive. Specific suggestions are made. 4. Intensive Therapy is offered to those who may require referral to a specialist originally proposed as a guide for sex therapists in 1970 (Annon 1976), the PLISSIT model has subsequently been applied in a range of different health contexts. [11], [12], [13], [14]

Nurses today conduct multiple roles, such as woman advocate, care provider, and research investigator., nurses developed their women's care responsibilities and promoted cancer control by developing their skills. Some sought to broaden the spectrum of care by investigating cervical cancer screening disparities, behavioral aspects of screening, and differences between the stated purposes of screening programs. [15]

Nurses among health care providers are in the first degree to whom women can easily explain themselves and can be effective in removing their concerns related sexual health. [16] Nurses have important duties as a counselor and guide in determining the factors affecting sexual functions of cancer patients, problems that may be experienced in sexual matters, and providing help to these individuals in order to get over these problems. [17], [18]

\subsection{Significance of the Study}

Egypt has a population of 28.37 million females ages 15 years and older who are at risk of developing cervical cancer. Current estimates indicate that every year 866a thousand females are diagnosed with cervical cancer and 373 a thousand die from cervical cancer. [19] Sexual oncology is gaining appreciation as a major area needing attention in nursing practice and research oncology nurses need to possess a high level of sensibility in dealing with womens 's sexual health needs. [20] However, sexual health care still inadequate addressed due to barriers such as incorrect assumptions and beliefs toward sexual issues. [21], [22]

One of the main roles of oncology nurses is to assess problems in this area to be able to provide anticipatory guidance related to treatment and the resumption of sexual activity, but this is one aspect of care that has been largely ignored by health care providers. Sexuality issues have not been adequately addressed by health care providers.

\subsection{Aim}

The study aimed to evaluate the effective of application of PLISSIT counseling model for women with cervical cancer undergoing treatment on enhancing Sexuality through:

1. Assessing the women's with cervical cancer, sexual functions, body image, and couple satisfaction to detect their needs.

2. Designing and implementing application of PLISSIT counseling model for women with cervical cancer according to women's needs

3. Evaluating the effect of the application of PLISSIT counseling model for women with cervical cancer on women's sexual functions, body image, and couple satisfaction.

\subsection{Study Hypothesis}

Cervical cancer women who have poor sexuality (sexual functioning, poor body image, and bad couple satisfaction) will experience an improvement in sexuality after application of PLISSIT counseling model post application compared to pre-application. 


\section{Subjects and Methods}

\subsection{Study Design}

A quasi-experimental (pre-post) study design was used.

\subsection{Study Setting}

The study was conducted in Out-patient Oncology general hospital, Helwan - Egypt.

\subsection{Subjects}

A purposive sample, composed of 80 women with cervical cancer was included and willing to participate and complete the study.

Inclusion criteria: All married women who diagnosed with cervical cancer undergoing different types of treatment, in all ages were recruited

Exclusion criteria: Gynecological tumor, e.g. vaginal, Breast and uterine cancer was excluded.

Sample size Equation: at 95\% confidence, power of the study. The researchers depended on the following equation to calculate the sample size:

$\mathrm{n}=\frac{\mathrm{NZ}^{2} \mathrm{P}(1-\mathrm{p})}{d^{2}(\mathrm{~N}-1)+Z^{2} \mathrm{P}(1-\mathrm{p})}$

$\mathrm{n}=\left(N Z^{\wedge}(2) \mathrm{P}(1-\mathrm{p})\right) /\left(\mathrm{d}^{\wedge} 2(\mathrm{~N}-1)+\mathrm{Z}^{\wedge}(2) \mathrm{P}(1-\mathrm{p})\right)$

$\mathrm{n}=$ Sample size

$\mathrm{N}=$ Total society size $=(190)$.

$\mathrm{D}=$ error percentage $=(0.5)$.

$\mathrm{P}=$ percentage of availability of the character and objectivity $=(0.1)$.

$\mathrm{Z}=$ the corresponding standard class of significance $95 \%=$ (1.96).

$$
\begin{aligned}
& \mathrm{n}=\frac{190(1.96)^{2} 0.1(1-0.1)}{(0.05)^{2}(190-1)+(1.96)^{2} 0.1(1-0.1)} \\
& \mathrm{n}=\frac{64.98}{0.81}=80 \\
& \mathrm{n}=64.98 / 0.81=80
\end{aligned}
$$

\subsection{Study Tools}

Fourth tools were used for data collection

Tool I: Structured interviewing questionnaire: which was developed by the researcher in the Arabic language based on a review of recent. It consisted of

Three parts:

1. Socio-demographic characteristics of women as age, level of education, marital status, occupation, parity, and residence.

2. The obstetric and medical history as regards: menstrual history

3. (Menopause, secondary amenorrhea), how cervical cancer was detected, stage of cervical cancer, type of treatment regimen, cervical cancer removal, types of surgery performed, and women undergone chemotherapy.

4. The side effect of cervical cancer treatment such as nausea and vomiting, diarrhea, loss of hair, dyspepsia, pain, bladder irritation, narrowing of the vagina, anemia, and fatigue.

Tool II. Female Sexual Function Index (FSDI). [23]

A multidimensional self - report questionnaire that assesses the key dimensions of female sexual function during the four weeks prior to the interview day. It comprises 19 multiple choice questions that measure 6 , domains, including desire domain (2 questions), arousal (4 questions), lubrication (4questions), orgasm (3 questions), satisfaction (3 questions) and sexual pain ( 3 questions). Each domain scored from $0 / 1$ (no sexual activity or sexual dysfunction, respectively) to 5 (suggestive of normal sexual activity). The domain score determined by adding the score of the questions that comprise the domain and multiply the sum by the domain factor (i.e., desire 0.6, arousal and lubrication 0.3 , orgasm, satisfaction and pain 0.4$)$. While the full-scale score calculated by adding the six domain scores (=2 to 36 ). For the present study, the researchers used the Arabic version FSFI that was translated by Anis et al. as it was validated for the Egyptian population. A total score of 28.1 was taken as the cutoff point for the Arabic version FSFI to distinguish between women with FSD and those with normal function (sensitivity $96.7 \%$, specificity $93.2 \%$ )

Tool III. Body Image Scale. [24] It is a self - report measure of the woman's body image. This 10-item scale was constructed in collaboration with the European Organization for Research and Treatment of Cancer (EORTC). The scale showed a high reliability (Cronbach's alpha 0.93) and good clinical validity. Scores on the body image range from 9 to 36. Good level was 9-17, a considerable level was 18-26 and bad level was 27-36. Lower scores indicate a greater level of body image. The scale was translated into Arabic language.

Tool IV. The Revised Dyadic Adjustment Scale (RDAS): [25] It is a self-report questionnaire about women and her husband's adjustment and satisfaction (it's taken from the woman's opinion). It assesses seven dimensions of couple relationship quality and satisfaction within three overarching categories including consensus in decision making, values and affection, satisfaction in the relationship with respect to stability and conflict regulation, and Cohesion. It included only 14 items, each of which asks the respondents to rate certain aspects of her/his relationship on a 5 or 6 point scale. Scores on the RDAS range from 0 to 69 with higher scores indicating greater relationship satisfaction and lower scores indicating greater relationship distress. The cut-off score for the RDAS is 48 such that scores of 48 and above indicate non-distress and scores of 47 and below indicate marital/relationship distress. The scale was translated into Arabic language.

Validity of the tools: Content validity was done through five experts from Faculty Members of Community, Maternal Health Nursing department and obstetrics medicine Specialty to ascertain relevance and completeness 
Reliability of the tools: Reliability coefficients were calculated for questionnaire items. The coefficient alpha was $76.00 \%$.

\subsection{Pilot Study}

A pilot study was conducted on $10 \%$ ( 8 women's) to test the content, clarity and time needed to fill the tool as a pretest. According to the pilot study, no modification was done. So, the pilot study sample was included in the study sample.

\subsection{Ethical Consideration}

Each women's were informed about the purpose and benefits of the study, then oral consent was obtained before starting the data collection. Strict confidentiality was ensured throughout the study process. The study subjects were assured that all data was used only for research purpose and women were informed of the rights to refuse or withdraw at any time with no consequences.

\subsection{Fieldwork}

- After official permissions to carry out the study, the aim of the study was explained to the selected subjects. The study was carried out a period of 6 months starting from the beginning of January 2015 till the end of June 2015 until the sample size attained.

- The average time consumed to fill tool was 30 minutes. The previously mentioned settings were visited by the researchers two days/week (Saturday and Thursday) from 10.00 am to $2.00 \mathrm{pm}$.

\section{The Application of PLISSIT Counseling Model Construction Included the Four Phases}

\subsection{Preparatory Phase}

The agreement for the participation of the subjects was taken after aims of the study have explained to the women's they were given as an opportunity to refuse to participate. The researcher was reassuring the women's that all the issues discussed will be confidential, used for research purpose only and for the sake of his loved one.

\subsection{Planning Phase}

General objective at the end of the application of PLISSIT counseling model will improve women sexual functioning, body image and couple satisfaction with cervical cancer undergoing treatment

- Determine learning contents of the of PLISSIT counseling models Choose teaching methods as discussion, role play, demonstration, pictures\& using simple Arabic language.

- Educational media as a laptop, video, and written materials are provided (booklet) as a mechanism to gain information and facilitate discussion.

\subsection{Implamentation Phase}

A six counseling sessions each session lasting 2 hours for three weeks, according toNami, Chun [26] was achieved through PLISSIT Figure 1, 2.

1. The first level is permission, which involves the nurses giving the women's permission to feel comfortable about a topic or permission to change their lifestyle or to get medical assistance. This level was created because many women's only require the permission to speak and voice their concerns about sexual issues in order to understand and move past them, often without needing the other levels of the model. The nurses, in acting as a receptive, nonjudgmental listening partner, allow the women's to discuss matters that would otherwise be too embarrassing for the individual to discuss.

2. The second level is limited information, where in the women's is supplied with limited and specific information on the topics of discussion. Because there is a significant amount of information available, nurses must learn what sexual topics the women's wishes to discuss, so that information, organizations, and support groups for those specific subjects can be provided.

3. The third level is specific suggestions, where the nurses give the women's suggestions related to the specific situations and assignments to do in order to help the women's fix the mental or health problem. This can include suggestions on how to deal with sex related diseases or information on how to better achieve sexual satisfaction by the women's changing their sexual behavior. The suggestions may be as simple as recommending exercise or can involve specific regimens of activity or medications.

4. The fourth and final level is intensive therapy, which has the nurses refer the women's to other mental and medical health professionals that can help the women's deal with the deeper, underlying issues and concerns being expressed. This level, with the onset of the internet age, may also refer to a nurses suggesting professional online resources for the women's to browse about their specific issue in a more private setting.

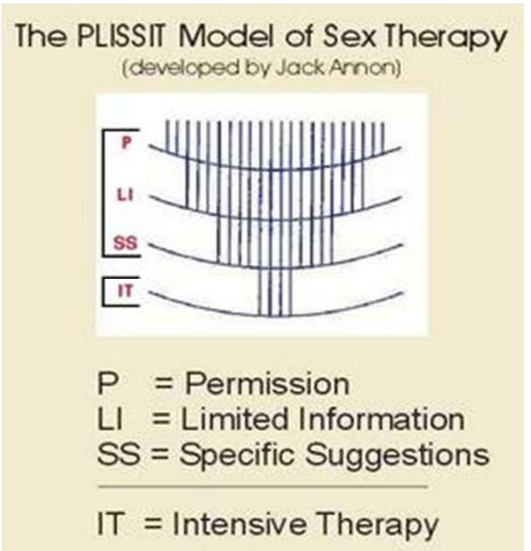

Figure 1. PLISSIT Counseling Model of Addressing Sexual Functioning. 
Jack, S., Annon, (1976). The PLISSIT model: A proposed conceptual scheme for the behavioral treatment of sexual problems. Journal of Sex Education and Therapy, 2 (2), 1-15. [27]

5. Nursing management: understanding cervical cancer treatment, and management of side effects (nausea, vomiting, diarrhea, dyspnea, gingivitis)

- Physical activity including walking for at least 30 minutes / day. Also, performing body range of motion exercise.

- Relaxation techniques including breathing exercise, distraction and recreation.

- Diet therapy (high fiber diet, low-fat diet, high vegetables/fruits diet).

6. After establishing a relationship with the woman, give them permission to openly discuss issues dealing with sexuality. Aske specific questions, starting with general ones before getting personal.

Use assessment and standardized instruments to a sexual problem.

Assess psychological function such as anxiety, and low self - esteem.

Discuss alternative sexual expressions for altered body image (functioning or structure)

\subsection{Evaluation Phase}

Evaluate the effectiveness of the pre/post phases after application of PLISSIT model was effective in enhancing sexual functioning, body image and couple satisfaction for cervical cancer women under treatment regimen.

\subsection{Statistical Analysis}

The collected data were organized, categorized, tabulated and analyzed. Data were presented in tables and charts using numbers and percentage, statistics and associations were done using mean, standard deviation $\mathrm{SD}$, t- test and $\mathrm{p}$ - value, Significant of the result: no Significant if $\mathrm{p}->0.05$, Significant if $\mathrm{p}-<0.05$ and Highly Significant if $\mathrm{p}-<0.001$.

\section{Results}

Table 1. Distribution of the studied sample according to their sociodemographic characteristics $(n=80)$.

\begin{tabular}{|c|c|c|}
\hline Variables & No & $\%$ \\
\hline \multicolumn{3}{|l|}{ Age (years): } \\
\hline $30-$ & 23 & 8.8 \\
\hline $40-$ & 41 & 51.5 \\
\hline $50-$ & 5 & 6.1 \\
\hline$\leq 60$ & 11 & 13.6 \\
\hline Mean \pm SD & & $42.11 \pm 10.02$ \\
\hline \multicolumn{3}{|l|}{ Level of education: } \\
\hline Illiterate & 6 & 7.2 \\
\hline Primary education & 17 & 21.3 \\
\hline Secondary education & 45 & 56.2 \\
\hline University education & 12 & 15.3 \\
\hline \multicolumn{3}{|l|}{ Marital Status: } \\
\hline Married & 80 & 100 \\
\hline \multicolumn{3}{|l|}{ Occupation: } \\
\hline Working & 51 & 63.8 \\
\hline Housewife & 29 & 36.2 \\
\hline \multicolumn{3}{|l|}{ Parity: } \\
\hline Nullipara & 54 & 67.5 \\
\hline One & 24 & 30 \\
\hline |Two & 2 & 2.5 \\
\hline \multicolumn{3}{|l|}{ Residence: } \\
\hline Urban & 55 & 68.7 \\
\hline Rural & 25 & 31.3 \\
\hline
\end{tabular}

Table 1 shows the general characteristics of the studied women with cervical cancer. It was found $51.5 \%$ their age ranged from 30 - years with mean age $42.11 \pm 10.02$ years. $56.2 \%$ had a secondary educational level, whereas only $7.2 \%$ Illiterate. As regards occupation, $63.8 \%$ of women were working. Regarding parity, 67.5 of women were nullipara and $68.7 \%$ were living in urban areas respectively.

Table 2. Distribution of the studied sample according to their obstetric and medical history $(n=80)$.

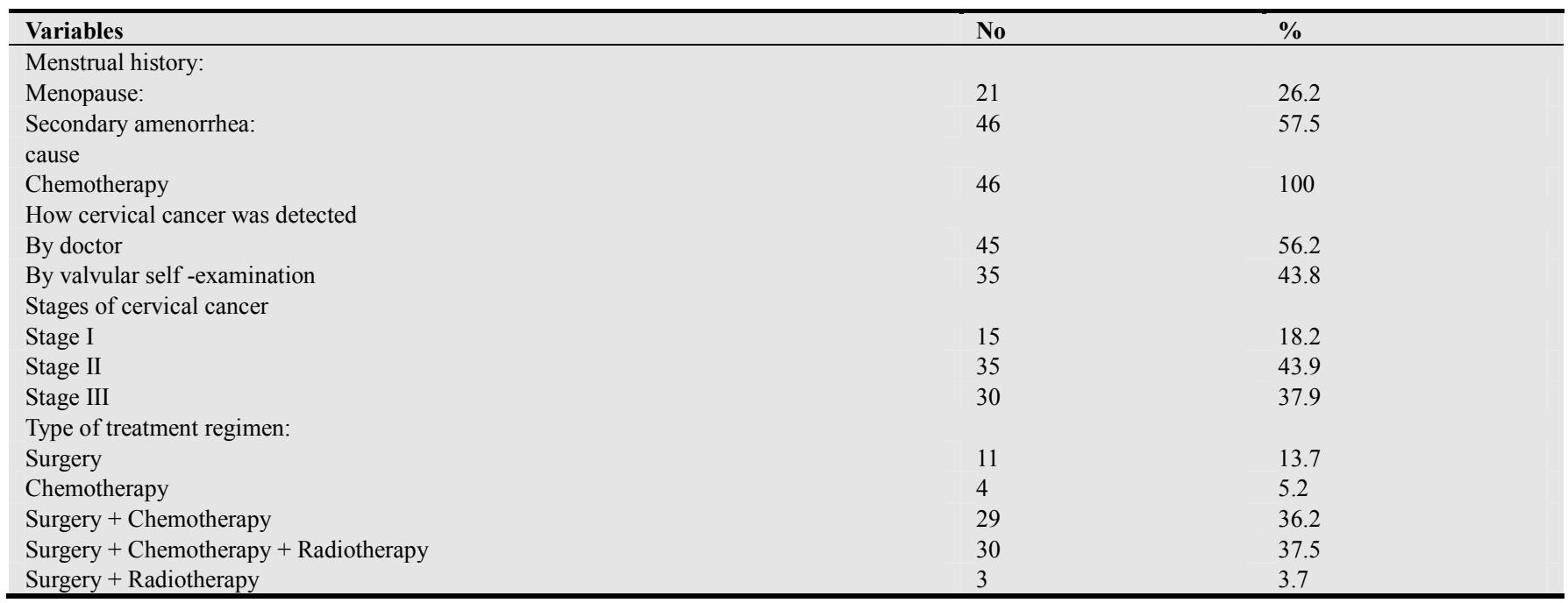




\begin{tabular}{lll}
\hline Variables & No & \% \\
\hline All & 3 & 3.7 \\
Cervical cancer removal: & 76 & 95 \\
If yes, type of surgery performed: & 12 & 15 \\
Cervical tumor excision only. & 68 & 85 \\
Hysterectomy (cervix and uterus). & 66 & 83.3 \\
Women undergone Chemotherapy: & & \\
\hline
\end{tabular}

Table 2 illustrates that $56.2 \%$ of the sample was detected cervical cancer by a doctor. Regarding medical data, about $43.9 \%$ and $37.9 \%$ were in cancer stage II, III respectively. Regarding the type of treatment, $37.5 \%$ of the studied sample was treated with surgery combined with chemotherapy and radiotherapy. 95.0\% of the studied sample underwent cervical tumor removal and $85.0 \%$ were having a Hysterectomy. Only, 15.0\% had excised cervical tumor only. Also, 83.3\% of the studied sample received chemotherapy.

Table 3. Distribution of the studied sample regarding side effects treatment of pre and post PLISSIT counseling model among women with cervical cancer $(n=80)$.

\begin{tabular}{|c|c|c|c|c|c|c|c|}
\hline \multirow{3}{*}{ Side effect of cervical cancer treatment } & \multicolumn{4}{|c|}{$\begin{array}{l}\text { The studied women with cervical cancer pre and post } \\
\text { PLISSIT }(n=80)\end{array}$} & \multirow{3}{*}{ Improvement } & \multirow{3}{*}{$\mathbf{X}^{2}$} & \multirow{3}{*}{ P-value } \\
\hline & \multicolumn{2}{|c|}{ Pre } & \multicolumn{2}{|c|}{ Post } & & & \\
\hline & No & $\%$ & No & $\%$ & & & \\
\hline Nausea and vomiting & 39 & 48.7 & 20 & 25.0 & 23.7 & 8.72 & $0.004 *$ \\
\hline Diarrhea & 32 & 40.0 & 15 & 18.8 & 21.2 & 6.64 & $0.010^{*}$ \\
\hline Loss of hair & 51 & 63.7 & 41 & 51.3 & 12.4 & 2.09 & 0.149 \\
\hline Pain & 53 & 65.2 & 34 & 42.5 & 22.7 & 7.97 & $0.005^{*}$ \\
\hline Bladder irritation & 45 & 56.1 & 32 & 40 & 16.1 & 3.71 & 0.054 \\
\hline Dyspnea & 33 & 41.3 & 20 & 25.0 & 16.3 & 3.86 & 0.050 \\
\hline Narrowing of the vagina & 45 & 56.1 & 35 & 43.8 & 12.3 & 1.85 & 0.173 \\
\hline Anemia & 36 & 45.0 & 27 & 33.8 & 11.2 & 1.21 & 0.242 \\
\hline Fatigue & 34 & 42.5 & 26 & 32.5 & 10.0 & 1.31 & 0.052 \\
\hline Gingivitis & 35 & 43.7 & 22 & 27.5 & 16.3 & 3.36 & 0.032 \\
\hline
\end{tabular}

*Significant $(\mathrm{P}<0.05)$.

Table 3 clarifies that, an improvement in treatment side effects after application of the PLISSIT counseling model. Meanwhile, there was statistically significant difference between treatment side effect pre and post application regarding nausea and vomiting, Diarrhea and Pain $(\mathrm{P}<0.05)$.

Table 4. Self- image scores pre and post PLISSIT counseling model among studied women with cervical cancer $(n=80)$.

\begin{tabular}{|c|c|c|c|c|c|c|}
\hline \multirow{3}{*}{ Self image scale } & \multicolumn{4}{|c|}{$\begin{array}{l}\text { The studied women with cervical cancer pre and post } \\
\text { PLISSIT }(\mathrm{n}=80)\end{array}$} & \multirow{3}{*}{$\mathbf{X}^{2}$} & \multirow{3}{*}{ P-value } \\
\hline & \multicolumn{2}{|l|}{ Pre } & \multicolumn{2}{|c|}{ Post } & & \\
\hline & No & $\%$ & No & $\%$ & & \\
\hline \multicolumn{7}{|l|}{ Body image scale level: } \\
\hline Good & 29 & 36.2 & 44 & 55.0 & & \\
\hline Considerable & 12 & 15.1 & 17 & 21.2 & & \\
\hline $\mathrm{Bad}$ & 39 & 48.7 & 19 & 23.8 & & \\
\hline Mean \pm SD & \multicolumn{2}{|c|}{$25.85 \pm 9.83$} & \multicolumn{2}{|c|}{$20.78 \pm 8.51$} & & \multirow{3}{*}{$0.000^{*}$} \\
\hline Paired t-test & \multicolumn{2}{|c|}{4.768} & & & \multirow{3}{*}{9.303} & \\
\hline P-value & 0.00 & & & & & \\
\hline Body image scale scores: & \multicolumn{2}{|c|}{$9-36$} & & & & \\
\hline $\begin{array}{l}\% \text { of improvement of body image scores } \\
\text { Range }\end{array}$ & \multicolumn{2}{|c|}{$75-140 \%$} & & & & \\
\hline Mean $\pm \mathrm{SD}$ & \multicolumn{2}{|c|}{$67.12 \% \pm 19.13$} & & & & \\
\hline
\end{tabular}

*Significant $(\mathrm{P}<0.05)$.

Table 4 shows that there was a statistically significant difference between body image scale level before and after application of the PLISSIT counseling model. $48.7 \%$ of the body image level was bad pre- application; it improved to become good 55.0\% post application. The mean scores of body image were $20.78 \pm 8.51$ after application of the PLISSIT counseling model compared to $25.85 \pm 9.83$ before this application. The range of body image scores improved was $75-140 \%$ after the application. 
Sahar Ahmed Shafik and Shaimaa Hassan Mohamady: Application of PLISSIT Counseling Model for Women with

Cervical Cancer Undergoing Treatment on Enhancing Sexuality

Table 5. Couple satisfaction pre and post PLISSIT counseling model application among studied women with cervical cancer ( $n=80)$.

\begin{tabular}{|c|c|c|c|c|c|c|}
\hline \multirow{3}{*}{ Couple Satisfaction } & \multicolumn{4}{|c|}{$\begin{array}{l}\text { The studied women with cervical cancer pre and post } \\
\text { PLISSIT }(n=80)\end{array}$} & \multirow{3}{*}{$\mathbf{X}^{2}$} & \multirow{3}{*}{ P-value } \\
\hline & \multicolumn{2}{|l|}{ Pre } & \multicolumn{2}{|c|}{ Post } & & \\
\hline & No & $\%$ & No & $\%$ & & \\
\hline \multicolumn{7}{|l|}{ Couple Satisfaction levels } \\
\hline Poor satisfaction $(0-<48)$ (Less adjusted) & 56 & 70.0 & 25 & 31.3 & & \\
\hline Satisfied ( $\geq 48$ ) (More adjusted) & 24 & 30.0 & 55 & 68.7 & & \\
\hline Couple satisfaction scores Range & \multicolumn{2}{|c|}{$10-69$} & \multicolumn{2}{|c|}{$22-69$} & & \\
\hline Paired t-test & \multicolumn{2}{|c|}{4.284} & & & $1 \% .803$ & $0.0001^{*}$ \\
\hline P-value & \multicolumn{2}{|c|}{$0.000 *$} & & & & \\
\hline$\%$ of improvement of total couple satisfaction scores: Range (9-36) & \multicolumn{2}{|c|}{$32.01 \%-220 \%$} & & & & \\
\hline Mean \pm SD & \multicolumn{2}{|c|}{$64.13 \pm 19.16$} & & & & \\
\hline
\end{tabular}

*Significant $(\mathrm{P}<0.05)$.

Table 5 displays that, there was a statistically significant difference in couple satisfaction before and after application of the PLISSIT model

$\mathrm{P}<0.0001$. The range of improvement of total couple satisfaction scores after application of the PLISSIT counseling model was $32.01 \%-220.0 \%$.

Table 6. Mean scores of female sexual function index (FSFI) pre and post PLISSIT counseling model among studied women with cervical cancer ( $n=80)$.

\begin{tabular}{|c|c|c|c|c|}
\hline \multirow{3}{*}{ Female Sexual Function Index (FSFI) } & \multicolumn{2}{|c|}{ The studied women with cervical cancer pre and post PLISSIT $(n=80)$} & \multirow{3}{*}{$Z$ value } & \multirow{3}{*}{ P-value } \\
\hline & Pre & Post & & \\
\hline & Mean \pm SD & Mean \pm SD & & \\
\hline \multicolumn{5}{|l|}{ FSFI main domain scores: } \\
\hline Desire & $1.45 \pm 1.55$ & $2.19 \pm 1.51$ & 1.623 & 0.108 \\
\hline Arousal & $1.96 \pm 2.05$ & $3.04 \pm 2.24$ & 2.884 & $0.005 *$ \\
\hline Lubrication & $1.99 \pm 2.16$ & $2.94 \pm 2.14$ & 2.547 & $0.0012 *$ \\
\hline Satisfaction & $1.55 \pm 1.59$ & $2.27 \pm 1.52$ & 2.665 & $0.009 *$ \\
\hline Pain & $2.27 \pm 2.16$ & $3.37 \pm 2.12$ & 2.962 & $0.004 *$ \\
\hline
\end{tabular}

Possible range scores for all domains were 0-6 except for the desire which it was 1.2-6.0 and for the total function was 2-36. * Significant $\mathrm{P}<0.05$.

Table 6 clarifies that, there was a statistically significant difference in the Female Sexual Function Index (FSFI) main domains, pre and post PLISSIT model application among the studied women. All domains (arousal, lubrication, orgasm, satisfaction, and pain) of FSFI $p<.05$ except with sexual desire, it is insignificant.

Table 7. Total Female Sexual Function Index (FSFI) scores pre and post PLISSIT counseling model among studied women with cervical cancer (n=80).

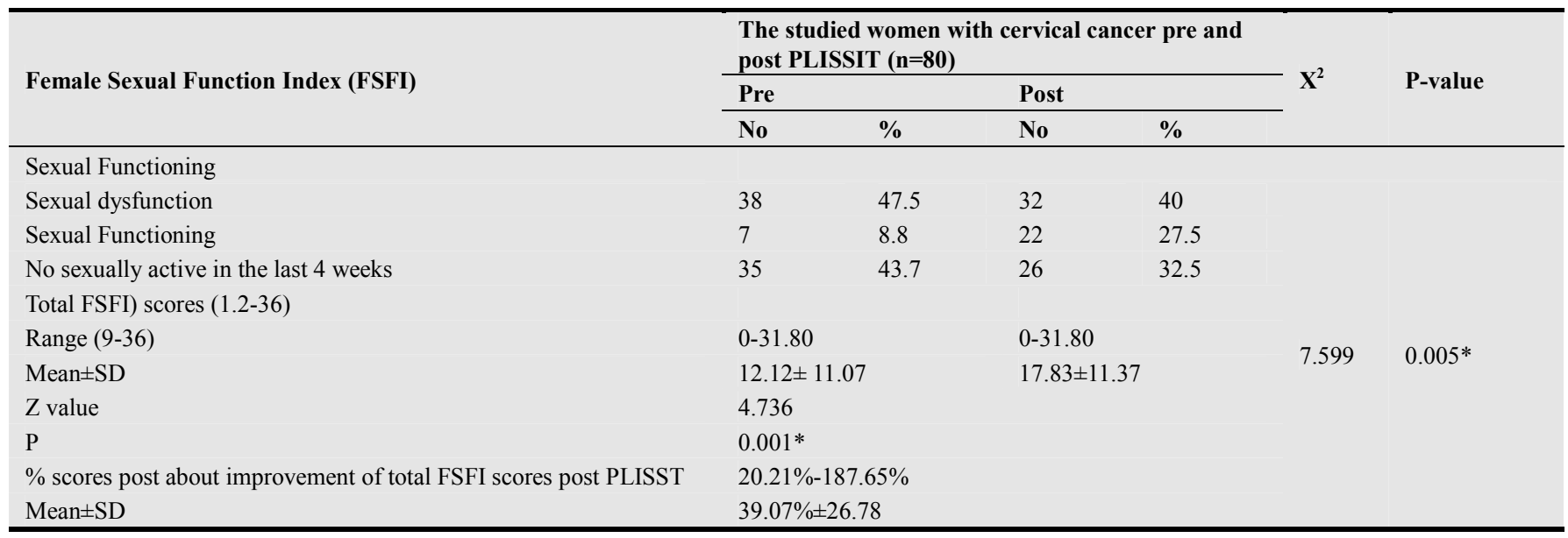

*Significant $(\mathrm{P}<0.05) . \mathrm{Z}$ value of Wilcoxon Signed Ranks Test

Table 7 showed that there was a statistically significant difference in total the Female Sexual Function Index FSFI, before and after application of the PLISSIT model among the studied women $\mathrm{P}<0.05$. The range of improvement of total FSFI scores post application was $20.20 \%-187.65 \%$. 
Table 8. The relationship between couple satisfaction, both body image and sexual functioning post PLISSIT application among studied women with cervical cancer $(n=80)$.

\begin{tabular}{|c|c|c|c|c|c|c|c|c|c|c|c|c|c|c|}
\hline \multirow{3}{*}{ Couple Satisfaction } & \multicolumn{6}{|l|}{ Pre } & \multicolumn{6}{|c|}{ Post } & \multirow{3}{*}{$X^{2}$} & \multirow{3}{*}{ P-value } \\
\hline & \multicolumn{2}{|c|}{$\begin{array}{l}\text { Sexsual } \\
\text { dysfunction } \\
(\mathbf{n}=38)\end{array}$} & \multicolumn{2}{|c|}{$\begin{array}{l}\text { Sexsually } \\
\text { functioning } \\
(\mathrm{n}=7)\end{array}$} & \multicolumn{2}{|c|}{$\begin{array}{l}\text { No Sexsual } \\
\text { Practice } \\
(n=35)\end{array}$} & \multicolumn{2}{|c|}{$\begin{array}{l}\text { Sexsual } \\
\text { dysfunction } \\
(\mathrm{n}=\mathbf{3 1})\end{array}$} & \multicolumn{2}{|c|}{$\begin{array}{l}\text { Sexsually } \\
\text { function } \\
(n=22)\end{array}$} & \multicolumn{2}{|c|}{$\begin{array}{l}\text { NoSexsual } \\
\text { Practic } \\
(\mathrm{n}=27)\end{array}$} & & \\
\hline & No & $\%$ & No & $\%$ & No & $\%$ & No & $\%$ & No & $\%$ & No & $\%$ & & \\
\hline Poor Satisfaction & 21 & 55.3 & 5 & 71.5 & 26 & 74.3 & 11 & 35.5 & 10 & 45.5 & 10 & 37.1 & \multirow{3}{*}{24.821} & \multirow{2}{*}{$0.0001 *$} \\
\hline Satisfied & 17 & 44.7 & 2 & 28.5 & 9 & 25.7 & 20 & 64.5 & 12 & 54.5 & 17 & 62.9 & & \\
\hline \multicolumn{14}{|l|}{ Body Image Scale } & \\
\hline Good (9-17) & 5 & 13.2 & 5 & 71.4 & 20 & 57.1 & 4 & 12.9 & 20 & 90.9 & 19 & 70.3 & \multirow{3}{*}{62.329} & \multirow{3}{*}{$0.0001 *$} \\
\hline Considerable (18-26) & 1 & 2.6 & 2 & 28.6 & 8 & 22.8 & 9 & 29.00 & 2 & 9.1 & 6 & 22.3 & & \\
\hline $\operatorname{Bad}(27-36)$ & 32 & 84.2 & 0 & 0.00 & 7 & 20.1 & 18 & 58.00 & 0 & 0.00 & 2 & 7.4 & & \\
\hline
\end{tabular}

Table 8 showed that there was a significant relationship between couple satisfaction and both body image and sexual functioning as a sexuality predictor $\mathrm{p}<0.05$. The same table showed a statistically significant difference and improvement of couple satisfaction and body image scale in relation to sexual functioning after application of PLISS than before.

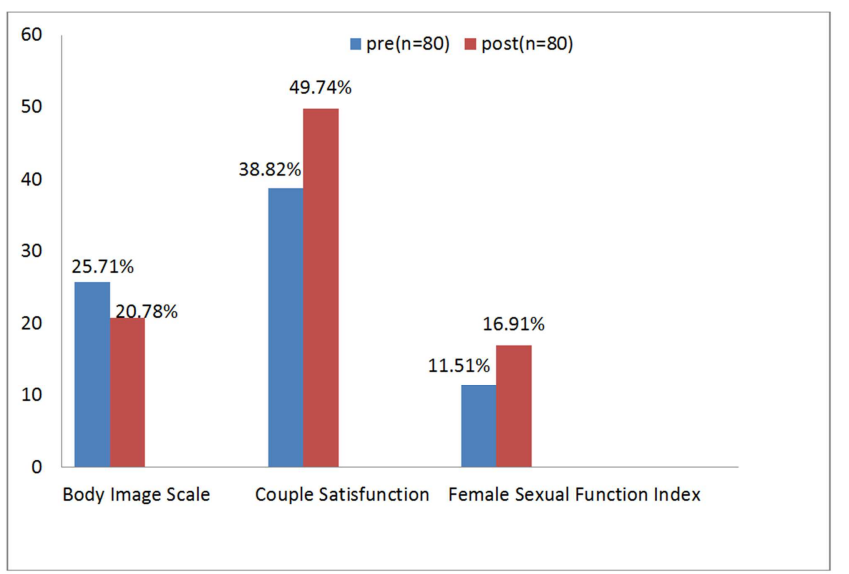

Figure 2. Reveals that Mean scores of body image scale, couple satisfaction and total Female Sexual Function Index (FSFI) pre and post PLISSIT counseling model among studied women with cervical cancer.

\section{Discussion}

Sexuality is a vital part of the quality of life and overall health. A cancer diagnosis can affect many aspects of women' daily routine, including their sexuality. Many oncology gynecological patients have fright and care about the fact that their marriage will be at risk and their sexual relationships with their partner will be influenced due to sexual problems that are caused by cancer and its treatment. [18], [28], [29]

Sexual dysfunction is common among women with cervical cancer. It affects all aspects of women's life. The majority of these problems can be treated in early stages with counseling and a few numbers of them need to be treated by specialists. [30]

The finding of the current study regarding sociodemographic characteristics of the studied group, the current results revealed that more than half of cervical cancer women age $40-<50$ years, with a mean age of $42.11 \pm 10.02$ years. This result was in the same line with Aktin and Ahmad (2014). [31] who mentioned that the mean ages of the cervical cancer women were $42.84 \pm 3.22$., Regarding the educational levels. More than half of them were in secondary education, while the majority of them were married while Less than two-thirds of women not working. This may be Embarrassment, lack of access to information, and low education are considered the main barriers for opening sexual discussion.

Regarding obstetric and medical history, which the cervical cancer women, the present study showed that, the nearly three-quarters of women with menopauses, more than half of women secondary amenorrhea. In a similar study done by Kotronoulas et al (2015). [22] who revealed that the majority of cervical cancer women menopauses or secondary amenorrhea. This may be resulting from the women receiving different types of cancer treatment.

The present study indicated that cervical cancer determinants were the stage of cancer. The majority of study women with cervical cancer were in stage II and III, Less than half of women treatment combined with surgery and chemotherapy, the majority of them the types of surgery hysterectomy (cervical and uterus). This finding was consistent with studies conducted by Shepherd et al (2014). [32] the majority of cervical cancer women treatment combined with surgery and chemotherapy, $87 \%$ of the study the types of surgery hysterectomy (cervical and uterus). These study findings were in agreement with Covens et al (2014). [33] who reported that the study it has been estimated that $45 \%$ of surgically treated stage II and III in cervical cancer occur in women who are under age 40.

Regarding the side effect of chemotherapy, the most of the women complain a side effect of treatment such as nausea and vomiting, diarrhea, loss of hair, pain, dyspepsia, bladder irritation, narrowing of the vagina, anemia, and fatigue before application of the PLISSIT counseling model. Improvement after application of PLISSIT counseling model. This improvement was statistically significantly different in pre-post PLISSIT counseling program. These findings were in the same line with On the same line, National Cancer 
Institute (2014). [7] reported that chemotherapy side effects were feelings of fatigue, apathy, nausea, vomiting and malaise and sleep or appetite disturbances and these effects interfere with libido. An improvement in all side effects after application of the PLISSIT counseling model appeared. With suggestions provided by the researchers during application the model, a problem- solving approach is useful to address an issue that the women have experienced personally and manage sexuality problem and side effects of treatment.

The present study finding showed that nearly half of the study sample had bad body image level. Improvement after application of PLISSIT counseling model. This improvement was statistically significantly different in pre-post PLISSIT counseling program. This result was consistent with Dempsey et al (2013). [6] found that hysterectomy resulted in changes in body image of women. Also. The present study finding was matched with Sewell and Edwards (2014). [5] found that the cervical cancer women diagnosis and treatment can bring changes related to women had a bad body image and sexuality, which improved after counseling program. Due to the efficacy of PLISSIT model for improving several residual effects of cervical cancer treatment on body image and sexuality.

The current study finding showed that the majority of study women had poor Couple satisfaction, before application of the PLISSIT counseling model. Improvement after application of PLISSIT counseling model. This improvement was statistically significantly different in prepost PLISSIT counseling program. This result was consistent with Zegwaard et al (2013). [34] found that who studied in cervical cancer women had poor Couple satisfaction resulting from estrogen deficiency. These symptoms can contribute to sexual difficulties and poor Couple satisfaction.

The current study indicated that cervical cancer affects many aspects of women's sexuality before application of the PLISSIT counseling model, Also, an improvement in all sexual function index domains (Desire, Arousal, Lubrication, Orgasm, pain, and satisfaction) post intervention except with sexual desire. This was in line with Gamal et al 2013. [35], chemotherapy can also have effects on cervical cancer women, especially in Desire, Arousal, Lubrication, Orgasm, pain, and satisfaction). This may be the majority of cervical cancer women wanted to discuss sexual matters but did not ask questions because they feared rejection or thought the setting was inappropriate for such discussion. Chun (2011). [36]: Results showed significant improvement in the Female Sexual Function Index FSFI sub-domain scores, including sexual desire $\mathrm{P}=0.048$, arousal $\mathrm{P}<0.001$, lubrication $\mathrm{P}<$ 0.001 , orgasm $\mathrm{P}=0.007$, and satisfaction $\mathrm{P}<0.001$. In a similar study done by Mansour et al (2014). [37] who revealed that there was statistically significant difference between pre- and post-application FSFI scores in the domains of desire $\mathrm{P}<0.001$, arousal $\mathrm{P}<0.001$, orgasm $\mathrm{P}=0.002$, satisfaction $\mathrm{P}<0.001$, and pain $\mathrm{P}<0.001$.

However, the results of the present study showed that altered body image had an effect on sexuality and couple satisfaction. This finding was congruent with Sewell \&
Edwards (2014). [5] Who reported that a treatment of gynecological cancer typically affects body parts associated with womanhood and femininity, causing considerable body changes that are likely to alter body image. After this treatment is completed, gynecological cancer patients are often left with the residual effects of surgery and/or various medical procedures, such as radiation and chemotherapy, that may affect on sexuality and couple satisfaction. On the other hand, Sacerdoti (2010). [38] found that women with cervical cancer often express fears and insecurity regarding both future sexual interactions and long-term side effects of treatment, which often impact their perceived sexual desirability. May due to the disease and treatment that can affect body image. These include, but are not limited to appearance alterations (e.g., hair loss, scarring, swelling), sensory changes (e.g., pain, numbness) and functional impairment (e.g., dysphagia, dysarthria, impotence). Juraskova et al., (2013). [29] showed that the importance of considering sexuality issues because sexuality and sexual health has been increasingly recognized as an integral aspect of quality of life during and after gynecologic cancer treatment.

\section{Conclusion}

The study and research hypothesis concluded that applying of PLISSIT counseling model for sexuality was effective in enhancing sexual functioning except in the area of sexual desire or libido, improvement in couple satisfaction and body image after application of PLISSIT counseling model post application compared to pre-application.

\section{Recommendations}

Based on the findings of this study, the following recommendations were suggested:

1. Dissemination of PLISSIT counseling model for women with cervical cancer in addressing sexual dysfunction in a cancer treatment.

2. Prepare a secure environment in the hospital outpatient units to discuss sexual problems with women freely.

3. Further researches are needed in other areas especially rural areas. To implement PLISSIT counseling model for women with cervical cancer undergoing treatment.

\section{References}

[1] Boyle, P, Levin, B., (2014): World Cancer Report 2008. IARC Cancer Treatment: cancer/news/new-screening-guidelines-forcervical-cancer. How Can Psychologists Help? Prof Psychol Res. 41 (6): 533-540.

[2] World Health Organization., (2011): Cancer fact sheet, available at: http://www.who.int/mediacentre./

[3] World Health Organization., (2012): Defining sexual health Report of a technical consultation on sexual health January, Geneva 31-28. 
[4] Katz, A., (2015): The Sounds of Silence: Sexuality Information for Cancer Patients. Journal of clinical oncology 23 (1): 66-68.

[5] Sewell, H. H, and Edwards, D. W., (2014): Pelvic genital cancer: Body image and sexuality. Front Radiat Ther Oncol (14): 35-41

[6] Dempsey, G. M, Buchsbaum, H. J, Morrison. J., (2013): Psychosocial adjustment to pelvic exenteration. Gynecol Oncol (3): 325-334.

[7] National Cancer Institute., (2014): PDQ treatment summary for health professionals. Cervical Cancer. Available at http://www.cancer.gov/

cancerinfo/pdq/treatment/cervical/healthprofessional.

Accessed 30

[8] Elena, S., Kelly, A, Peter E., and Mary, J., (2014): Sexuality and intimacy after gynecological cancer Maturities, factsheets/fs297/en/index.html.

[9] Hollingsworth, M, and Berman, F., (2013): The role of androgens in female sexual dysfunction, American Society for Reproductive Medicine (1): 27-30.

[10] Gölbaşı, Z, and Evcili, F., (2013): Evaluating patient sexuality and nursing: Obstacles and suggestions. Anatolian J Nursing Health Sciences, (16): 313-321.

[11] Weijmer, W. C., and Van de Wiel, H. B., (2013): Sexuality, intimacy, and gynecological cancer. J Sex Marital (1): 121128.

[12] Madorsky, J. G. B. and Dixon, T. P., (2010): Rehabilitation aspects of human sexuality. The Western Journal of Medicine, (139): 174-176.

[13] Wallace, M. A., (2012): Assessment of sexual health in older adults. American Journal of Nursing, (7): 52-60.

[14] Ibrahim, I., Hussein, M., Khaled, N., Mikhail, N. H., Baraka, H., Hossam, K., and Amal, S., (2014): Cancer Incidence in Egypt: Results of the National Population-Based Cancer Registry Program. Journal of Cancer Epidemiology, 1-18.

[15] American Cancer Society., (2013): New screening guidelines for cervical cancer. Retrieved from http://www.cancer.org/at:.www.hpvcentre.net/statistics/reports /EGY_FS.pdf.

[16] Taylor, B, and Davis, S., (2011): Using the extended PLISSIT model to address sexual healthcare needs. Nurs. Standard, (21): 35-40.

[17] Jolley, S., (2012): Taking a sexual history: the role of the nurse. Nursing Times, (98): 39-41.

[18] Dattilo, J, and Brewer, M. K., (2015): Assessing clients' sexual health as a component of holistic nursing practice Senior nursing students share their experiences. J. Holist Nurs, (23): 208-219.

[19] ICO Information Centre on HPV and Cancer., (2014): Human Papillomavirus and Related Cancers, Fact Sheet 2013, Available.

[20] Kim, S., Kang, H. S., and Kim, J. H., (2011): A sexual health care attitude scale for nurses: Development and psychometric evaluation International Journal of Nursing Studies, (48): $1522-1532$.
[21] Julien, J. O., Thom, B., and Kline, N. E., (2010): Identification of barriers to sexual health assessment inoncology nursing practice. Oncology Nursing Forum, (3): 186-190.

[22] Kotronoulas, G, Papadopoulou, C, and Patiraki, E., (2015): Nurses' knowledge, attitudes, and practices regarding provision of sexual health care in patients with cancer: critical review of the evidence. Support Care Cancer. 17: 479-501.

[23] Anis, T. H., Gheit, S. A., Saied, H. S., and Al kherbash, S. A., (2011): Arabic translation of Female Sexual Function Index and validation in an Egyptian population. J Sex Med., (12): 3370-3378.

[24] Hopwood, P., Fletcher, I., Lee, A., and Al Ghazal, S. A. (2001): Body image scale for use with cancer patients. European Journal of Cancer, (37): 189-197.

[25] Crane, D. R., Middleton, K. C., and Bean, R. A., (2000): Establishing criterion scores for the Marital Satisfaction Scale and the Revised Dyadic Adjustment Scale. American Journal of Family Therapy, (1): 53-60.

[26] Nami, C., (2011): Effectiveness of plissit model sexual program on female sexual function for women with gynecologic cancer. Journal Korean Academic Nursing. (4): 471-480.

[27] Jack, S., Annon., (1976): The PLISSIT model: A proposed conceptual scheme for the behavioral treatment of sexual problems. Journal of Sex Education and Therapy, 2 (2): 1-15.

[28] Quinn, C., and Browne, G., (2011): Sexuality of people living with mental illness: a collaborative challenge for mental health nurses. Int J Ment Health Nurse, (18): 195-203.

[29] Juraskova, I, Butow, P., and Robertson, R., (2013): Posttreatment sexual adjustment following cervical and endometrial cancer: a qualitative insight. Psycho-Oncology, (12): $267-279$.

[30] Nakopoulou, E., Papaharitou S., and Hatzichristou, D., (2013): Patients' sexual health: a qualitative research approach on Greek nurses' perceptions. The Journal of Sexual Medicine 6 (8): 2124-2132.

[31] Atkin, K., and Ahmad, W., (2014): Family care-giving and chronic illness: how parents cope with a child with a sickle cell disorder orcervical cancer, Health and Social Care in the Community, (1): 57-69.

[32] Shepherd, J. H., Crawford, R. A., and Oram, D. H., (2014): Radical trachelectomy: A way to preserve fertility in the treatment of early cervical cancer. Br J Obstet Gynaecol (105): 912-916, (17): 479-501. Standard, (21): 35-40.

[33] Covens, A., Rosen. B., and Murphy. J., (2014): Changes in the demographics and perioperative care of stage IA (2)/IB (1) cervical cancer over the past 16 years. Gynecol Oncol (81): 133- 137.

[34] Zegwaard, M. I., Gamel, C. J., and Durgis, D. J., (2013): The experience of sexuality and information received in women with cervical cancer and their partners. Verpleegkunde, (15): $18-27$.

[35] Gamel, C., Hengeveld, M., and Davis, B., (2013): Informational needs about the effects of gynecological cancer on sexuality: A review of the literature. J Clin Nurs (9): 678688. 
[36] Chun, N., (2011): Effectiveness of PLISSIT model sexual program on female sexual function for women with gynecologic cancer. J Korean Acad Nurs. (41): 471-80.

[37] Mansour, S. E., Shebl, A. M., and Waheda, S. M., (2014): The effect of sexual counseling program on pain level and sexual function among women with dyspareunia. J Educ Prac (5): 208-220.
[38] Sacerdoti, R., C., Lagana, L., and Koopman, C., (2010): The effect of educational program on increasing cervical cancer screening behavior among women in Hamadan, Iran: Applying Health Belief Model, Journal of Research in Health Sciences, (1): 20-25. 